\title{
O homem duplicado e a estética pós-modernista
}

\author{
Seleste Michels da Rosa
}

\begin{abstract}
Resumo: Este ensaio pretende fazer aproximações entre a estética do pós-modernismo e a obra $O$ homem duplicado de José Saramago. Partiremos de uma análise formal a fim de esclarecer o conteúdo. Percebemos, através da leitura da obra referida, que a forma é estreitamente conformada ao conteúdo, por isso iniciaremos a análise pela linguagem usada pelo autor, que traz uma pontuação diversa da convencional. O discurso é direto e surge quase colado à voz do narrador pela falta da pontuação convencional. Há também muita intertextualidade interna e externa à própria obra, como a retomada do mito de Tróia. Através desses aspectos e de seus dois protagonistas, o ator e o professor, há a retomada da discussão pós-moderna entre a história 'mítica' ou individual e a história oficial, além de retomar a própria tradição portuguesa na problematização da retomada histórica.
\end{abstract}

Palavras-chave: Pós-modernismo; O Homem Duplicado; História; Literatura.

\begin{abstract}
This essay intends to bridge the postmodernism aesthetic and this work by Jose Saramago. We are going to perform a formal analysis in order to understand the content. Through the reading of this work we realized that the form is strictly adapted to the content and therefore we will start the analysis from the language that was used by the author, which presents a form of punctuation that is different from the regular punctuation. It is a direct speech, which seems to be glued to the narrator's voice as a result of the unconventional punctuation. It also presents a high degree of both internal and external intertextuality, such as the recovery of the myth of Troy. Through this and also through its two protagonists, the actor and the professor, the post-modern debate between the "mythical" or individual history and the official history takes place again, as well as the very Portuguese tradition regarding the historical recovery issue.
\end{abstract}

Keywords: Post-modernism; The double; History; Literature.

A narrativa, $O$ homem duplicado, é altamente instigante, por possuir um apurado trabalho para contar a história de um sujeito, professor de história, que encontra um homem que é sua cópia fiel e perfeita, sem que seja seu irmão gêmeo, na figura de um ator. Também chama a atenção a estilística usada pelo autor que deixa o texto bastante complexo e multifacetado. Sua maneira de pontuar, ou não pontuar, possibilita a diversificação dos caminhos de interpretação. Há também a abertura de possibilidades de interpretação pelo uso do discurso direto que não predomina e que, quando é usado, não traz pontuação que o distinga do discurso direto. A polifonia da obra, conforme Bakthin, também é garantida já que a posição de todos os personagens é colocada sem nenhuma evidente tomada de posição do narrador.

\footnotetext{
* Seleste Michels Rosa é mestranda do Programa de Pós-Graduação em Letras da UFRGS.
} 
É notável o uso de dois tipos de intertextualidade: a do discurso popular, bastante evidente e repetida, e também a do tipo literário, como ocorre com Hamlet, e $O$ delfim, metaficção historiográfica de José Cardoso Pires. Nesse texto, o jogo intertextual se dá através da metáfora da lagartixa, criada por Pires e retraduzida por Saramago. Em Pires o tempo, estagnado em Portugal, é representado por uma lagartixa:

Espalmada na inscrição imperial havia uma lagartixa. Parda, imóvel, parecia um estilhaço de pedra sobre outra pedra maior e mais antiga, mas, como todas as lagartixas, um estilhaço sensível e vivaz debaixo daquele sono aparente. Pensei: o tempo, o nosso tempo amesquinhado. [...] Lagartixa, meu brasão do tempo. (PIRES, 1975, p. 80-81.).

A referência de Saramago tem um tom notavelmente irônico, e sua lagartixa representa a história, cortada e regenerada ao longo do tempo, com muitos "rabos de fora", ou seja, fatos excluídos da oficial História. Partindo dessa referência, chegamos a um tema bastante comum na literatura portuguesa que é a retomada histórica; uma tradição formada nos romances históricos do século XVIII e mantida no país de forma especial. No texto de Saramago, Tertuliano é o representante da história contada nos colégios, como mostra a citação a seguir:

A História que Tertuliano Máximo Afonso tem a missão de ensinar é como um bonsai a que de vez em quando se aparam as raízes para que não cresça, uma miniatura infantil da gigantesca árvore dos lugares e do tempo [...] nem sequer um diminuto beija-flor, conseguiria fazer ninho nos ramos de um bonsai, e se é verdade que a sombra deste, supondo-o provido de suficiente frondosidade, pode ir acoitar-se uma lagartixa, o mais certo é que ao réptil lhe fique a ponta do rabo de fora. A História que Tertuliano Máximo Afonso ensina, ele mesmo o reconhece e não se importará de confessar se lho perguntarem, tem uma enorme quantidade de rabos de fora, alguns ainda remexendo, outros já reduzidos a uma pele encarquilhada como uma carreirinha de vértebras solta dentro. (SARAMAGO, 2002, p. 15-16.).

É interessante, também, enquanto característica pós-moderna, a retomada do mito, nesse caso, mito do duplo e do nó da guerra de Tróia; além da fragmentação do sujeito e o evidente questionamento da forma clássica. A retomada dessa forma se dá com a presença do coro, aqui simplesmente nomeado de Senso comum, e principalmente com o herói que possui uma trajetória totalmente enquadrada na definição aristotélica, que vai da fortuna ao infortúnio por causa de uma desmedida: o professor não quer ser um homem comum, ele quer ser especial, único; e, ao mesmo tempo, não ser único, por ser duplo.

É notável ainda o conflito entre história e literatura. Os estudos pós-modernos problematizam a narrativa histórica, questionam o quanto ela se distancia da escrita literária e se tal distanciamento realmente existe. Diz Umberto Eco (1991) sobre o assunto: “A resposta pós-moderna ao moderno consiste em reconhecer que o passado, como não pode ser realmente destruído porque sua destruição conduz ao silêncio [a descoberto do modernismo], precisa ser reavaliado: mas com ironia, e não com inocência." (ECO apud HUTCHEON, 
1991, p.124.). E é isso que a metaficção historiográfica vem fazendo, retomando temas históricos e brincando com as verdades históricas, que é o que Saramago faz nessa obra de maneira plenamente realizada.

Para chegar a essas formas de questionamento, a escrita contemporânea lança mão de uma nova estética, que traz um novo modelo. O pós-modernismo é contra os modelos, e cria um modelo 'contra-modelo', levando à idéia de obra aberta, como proposta de um campo de possibilidades interpretativas, como configuração de estímulos dotados de uma substancial indeterminação, de maneira a induzir o fruidor a uma série de leituras sempre variáveis Temos, enfim, uma estrutura, que se assemelha a uma 'constelação' de elementos que se prestam a diversas relações recíprocas. (ECO apud HUTCHEON, 1991, p.150).

Vemos que as questões de linguagem são as primeiras que se colocam e elas chocam o leitor logo nas primeiras páginas. As palavras são postas na folha sem se aterem ao formato normal, isto é, existem poucos pontos finais. A maioria da pontuação é feita por vírgulas, e há o uso, algumas vezes, de letra maiúscula mesmo sem que a sentença seja iniciada por nomes próprios. Fica claro que o autor não pretende seguir um padrão gramatical de pontuação, e a ausência de padronização causa uma confusão no leitor que, em alguns momentos, não sabe que caminho seguir. Essa construção aliada a outros fatores cria mais rotas de interpretação, formulando um discurso aberto que é um chamado à responsabilidade, à escolha individual, é um desafio e um estímulo para a imaginação e para a inteligência. Por isso a arte contemporânea é sempre difícil e imprevisível, não quer agradar e consolar, quer colocar problemas, renovar nossa percepção e o nosso modo de compreender as coisas, gerar uma sensação de desconforto frente ao mundo e exige um esforço do leitor para conseguir o entendimento. Assim, o autor faz com que ele perceba as dubiedades do texto.

Predomina na narrativa um narrador em terceira pessoa que conduz o texto, gerando um paradoxo já que sua utilização não é comum em obras pós-modernas, pois a sua onisciência acaba com a multiplicidade de interpretação do texto já que expressa a sua visão sobre o enredo e os personagens. Todavia, esse é mais um dos questionamentos metanarrativos que o autor traz para o texto. Através de um narrador do tipo clássico, ele se esforça em mostrar para o leitor a sua tentativa de manter a imparcialidade, inclusive a do leitor, pedindo-lhe explicitamente que não simpatize mais com um dos sósias do que com outro. Todavia, conforme o conflito vai se consolidando, ele vai dando mais espaço para o discurso direto entre os personagens, permitindo que o leitor entre em contato imediato com eles.

O discurso direto é o elemento que fica longe da configuração esperada, não há marcação de início e fim de falas. Um personagem fala, o outro responde, mas não são 
apontadas as limitações. A falta de demarcação é uma das estratégias do autor para proporcionar uma obra múltipla, causando confusão no momento de atribuir a fala a um ou outro personagem.Vejamos um exemplo:

Poderei falar com o senhor Daniel Santa-Clara, perguntou Tertuliano Máximo Afonso quando a mulher dele atendeu, Suponho que é a mesma pessoa que ligou para aqui noutro dia, estou a reconhecê-lo pela voz, disse ela, Sim, sou eu, O nome, por favor. Não creio que mereça a pena, o seu marido não me conhece. Também o senhor não o conhece a ele, e apesar disso sabe como se chama, É natural, ele é actor, portanto uma figura pública. (SARAMAGO, 2002, p.177).

Inicialmente o autor se preocupa em deixar bastante evidente quem disse o que, entretanto, no decorrer do discurso, ele abandona os apontamentos e, na altura que eles dizem a última frase, "É natural, é actor", não podemos afirmar peremptoriamente quem fez tal afirmação. Por isso a obra ganha mais possibilidades de leitura, e a presença reiterada desse recurso utilizado vai abrindo cada vez mais multiplicidade num mesmo diálogo.

A metalinguagem, outro atributo da estética contemporânea, também é bastante presente. Na página 61, o narrador faz toda uma incursão pela criação da linguagem, ou melhor, pela sua ausência e como ela faria falta se não pudéssemos dizer nada, nem as coisas mais básicas. Entre as páginas 148 e 149 temos, no diálogo entre os professores, a configuração do sentido de certas expressões populares e de como elas eram usadas na casa de um e de outro, concluindo que há bastante variação no uso desse tipo de forma. Os professores fazem uma pequena pesquisa lingüística que demonstra a preocupação do autor com estudo da linguagem. A linguagem popular parece ser um aspecto relevante para ele, já que nesses momentos a controvérsia metalingüística não é intrínseca ao enredo.

A linguagem usada no texto parece manter um nível bastante coloquial para o português castiço, o que é provado por algumas redundâncias, como: "Também o senhor não o conhece a ele", ocorrência típica da linguagem falada. Outra marca interessante está na fala: "nem te vi nem te conheço"(SARAMAGO, 2002, p.31), uma expressão bastante coloquial, conforme lembrado por Luzia Reis:

Descontinuidade; quebra da sequiência previsível; utilização de todas as linguagens [...]; incorporação num mesmo texto, de fragmentos diversos, de vários autores, estilos e épocas, etc., realizando o que se chama intertextualidade; simultaneidade de cenas, imitando procedimentos do cinema moderno; introdução, na prosa, de técnicas de construção de poemas; inclusão, na composição do texto, de posicionamentos autocríticos [...]. (REIS, 1987, p. 86.).

Vemos, a partir dessa citação, que o pós-modernismo quer fazer uso dos dialetos menos favorecidos, enfim, da fala marginalizada e posta de fora do cânone por não estar versada conforme querem a gramática e a norma culta. Em busca da linguagem tipicamente popular, o autor faz uso de diversos ditados populares, alguns facilmente identificáveis, outros nem tanto, principalmente, por serem expressões típicas de Portugal. Mas a leitura desses 
ditos com certeza contribui de forma central para a leitura do texto. Por isso seguimos as indicações de leitura que a presença deles nos trazem.

O primeiro ditado e o mais evidente é o nome do primeiro filme que Tertuliano vai assistir e a partir do qual descobre que tem um sósia. "Quem porfia mata a caça" que, em português do Brasil, assemelha-se talvez a "Quem espera sempre alcança"; não bem especificamente, pois porfiar significa 'lutar até conseguir', e o protagonista é insistente e teimoso. É uma alusão ao personagem Tertuliano que não espera, não deixa as coisas acontecerem ao natural, mas vai buscar, nesse caso, conflitos. Tertuliano é um angustiado, uma pessoa obstinada que decidiu descobrir quem é seu sósia e para isso não mede esforços, ele constrói sua própria história. Desta forma, ele age contra seu destino, na concepção grega, criando uma desmedida, pela qual será castigado posteriormente.

O ditado seguinte marca a presença de um destino previamente estabelecido, "nunca jogues as pêras com o destino, que ele come as maduras e dá-te as verdes"(SARAMAGO, 2002, p.16). Aqui podemos ver uma previsão do que acontecerá com o personagem principal. Tal qual um herói grego ele tem direito a um oráculo, dito por sua mãe, que prediz como será seu fim. Mas, ainda assim decide escolher seu próprio destino. É um herói trágico nesse sentido. Parece que ele está muito além de sua posição de simples professor de história, ele sabe que pode mais e ambiciona outros destinos e, por isso, o destino lhe aplicará o castigo final. O romance remete à forma clássica, onde as moiras determinam um caminho e qualquer desmedida é motivo para um castigo cruel. A desmedida de Tertuliano é a sua aproximação a António Claro:

Tertuliano Máximo Afonso, até esses dias pacífico professor de História do ensino secundário, demonstra ser dotado de suficiente talento para o exercício de qualquer destas duas actividades profissionais, ou a de disfarçado delinqüente, ou a do polícia que o investiga. Demos nós tempo ao tempo, e saberemos qual das duas vocações prevalecerá. (SARAMAGO, 2002, p.165.).

A dubiedade do personagem Tertuliano, duplicidade ou multiplicidade, que está presente no seu nome já traz em si essa concepção. Cada um dos três — Tertuliano, Máximo e Afonso - são nomes próprios independentes, podem ser pessoas diferentes, com personalidade e vocações distintas. Esse nome, dito e repetido já na primeira página, indica o caminho do personagem: ele não está sozinho. Até mesmo em sua casa ele, percebe a presença de outros que se revelam desde a primeira noite em que acompanhamos sua trajetória. Além desse índice, o autor nunca o chama só pelo primeiro nome, ele sempre se refere a Tertuliano Máximo Afonso, talvez como se quisesse propor: todos eles. As obras de Saramago costumam dar especial atenção e significado para os nomes, por isso é válida uma tentativa de analisá-los. 
Partindo desse princípio, podemos atribuir outro sentido pós-moderno para escolha desse nome múltiplo: a fragmentação do sujeito, presente desde a origem do romance, e cada vez mais forte e valorizada na escrita contemporânea. O sujeito contemporâneo é múltiplo por essência, os tipos estão cada vez mais em extinção. A complexidade do mundo é bem maior: as grandes verdades caíram por terra, não existe mais um único discurso verdadeiro. Por isso, ficou muito mais difícil caracterizar um indivíduo, já não é suficiente dizer, por exemplo, que ele é 'um professor de história'; o que poderia muito bem defini-lo no século passado, hoje, é insuficiente. Ele pode ser professor e ainda assim ser medíocre, como de fato é o personagem; até sua namorada bancária tem concepções filosóficas mais prolixas que as suas. Ou seja, ele não é só professor de história, ele é apático e obstinado, complacente e inconformado, simultaneamente; ou seja, não configura um tipo: professor-de-história.

O personagem, não coincidentemente, tem o nome composto de três nomes de origem totalmente diversa, segundo um dicionário de nomes (STRAHLER, 02/12/05). 'Tertuliano' é originário do hebraico e significa falso ministro, logo o primeiro nome já se refere à falsidade. Uma questão sempre levantada, nos textos pós-modernos, é a veracidade das postulações, o autor pode estar indicando que nosso protagonista é uma cópia, algo falso. Há uma fala de Tertuliano que assegura um pouco essa leitura: "Serei mesmo um erro, perguntou-se, e, supondo que efectivamente o sou, que significado, que conseqüências para um ser humano terá saber-se errado." (SARAMAGO, 2002, p. 28.).

Seu segundo nome 'Máximo', proveniente do latim, significa o maior, superlativo de mágnus. Então, compondo o nome, é ele uma cópia maior, poderíamos dizer 'a maior fraude'. Ou, pensando separado, ele seria literalmente o máximo, coisa que ele não é, pois é um sujeito medíocre. Contudo não sabemos se, seguindo por outro caminho, ele não atingisse o ápice, afinal é dito que ele tem talento para ator, assim com António Claro e até é bem bonito. Mas este também é um ator medíocre, sendo, assim, o nome ‘máximo' seria uma grande ironia.

O último nome é Afonso oriundo da língua germânica e significa caprichoso, voluntarioso; isso sim, é evidente que nosso personagem é, ele só faz o que deseja, age somente por vontade própria, não segue prescrições de comportamento prévias. Ela passa todo tempo a maltratar Maria da Paz, mulher que o ama e que, por fim, ele descobre amar. Sua mãe também sofre com sua voluntariedade, ele inventa desculpas para não ligar para ela e não ir visitá-la. Poderíamos dizer que é um homem demasiadamente mimado por sua mãe e namorada que se deixam moldar às vontades de Tertuliano.

Um ponto relevante é a industrialização da sociedade contemporânea. A expressão da terceira onda capitalista, ou seja, o capitalismo que tardio trouxe consigo um novo 
entendimento sobre a mercadoria: o fetichismo da mercadoria. Nesse fetichismo, as mercadorias são tratadas como seres humanos, ou são convertidas em coisas marcadas de beleza excepcional e até em objeto de profundo apego afetivo. $\mathrm{O}$ autor problematiza esse sentimento fazendo com que o personagem se veja duplicado, ou seja, produzido em série, o que não é humano; a humanidade quer individualidade. Também é problemático o lugar de António Claro que é um produto, uma pessoa que vende sua própria imagem, justamente o que ele e Tertuliano compartilham. Por fim, o que apóia essa leitura é o aparecimento de mais um sósia após a morte de António Claro, significando que a produção continua acontecendo, e só é descoberta porque António Claro é ator e tem exposição na mídia: a mídia multiplica as imagens.

Voltando aos ditados, o terceiro é “....a ordem, como do cão se diz também, é amiga do homem... Ter um lugar pra cada coisa e cada coisa no seu lugar”. Esse levanta outra questão pós-moderna: o questionamento da História. Parece-nos que o autor faz um jogo de metalinguagem, usando os dois personagens duplos como personificação de dois conceitos: História e Literatura. Tertuliano, professor de história, organizado, que mantém a ordem cronológica até para assistir os filmes, é o personagem que representa a História, já António, mestre na área do mascaramento, da invenção, da atuação faz às vezes da Literatura. O livro todo é uma discussão metalingüística a respeito da precedência da História sobre a Literatura ou vice-versa. Interessante perceber que o romance, apesar de romance, persegue o professor de história.

Todo o conflito dos personagens em saber quem nasceu primeiro e, portanto, tem a primogenitura e a primazia aponta para um discurso filosófico, quem afinal é o primeiro: a História ou Literatura. Há "uma espécie de consciência de primogenitura que neste momento se está rebelando contra a ameaça, como se um ambicioso irmão bastardo aí viesse para apear o trono"(SARAMAGO, 2002). A importância desse dado é tão grande que, no primeiro encontro, eles querem ver os documentos um do outro para saber quem nasceu primeiro. Descobrem que nasceram no mesmo dia, assim resta saber a hora que nasceram, mas isso não está registrado nos documentos. Tertuliano diz seu horário de nascimento primeiro, e, assim não sabemos se António inventou ou não que nasceu antes, tendo em vista que este personagem não é honesto.

A partir disso existe a retomada do conceito de metaficção historiográfica, categoria própria do Pós - Modernismo, conforme Machado:

Assim, embora destaque Hutcheon (1991, p.141) que as recentes leituras críticas da história e da ficção têm se concentrado mais naquilo que as duas formas de escrita têm em comum do que em suas diferenças, o aprofundamento da problemática leva à necessidade de uma reflexão 
que, a partir de uma análise comparativa, destaque os elementos especificadores do estatuto formal e epistemológico de cada um dos gêneros. (MACHADO, 16/11/05).

Por isso, o autor está inserido nessa infusão de tendências que é o Pós- Modernismo e quer problematizar a questão da veracidade da História. Vemos, em Jameson (1997) que, na era que estamos vivendo, o capitalismo tardio, os saberes narrativos precisam de veracidade, eles não são mais válidos por si mesmo, pelo simples fato de existirem. A quantidade de informação disponível através dos modernos meios de comunicação e facilidade de criá-las e publicá-las faz com que haja a necessidade da verificação da autoridade que o indivíduo tem para proferir aquele enunciado. Esse questionamento acontece com a História, pois ela é um saber narrativo e, enquanto narrativa, cria um fato histórico, já que o acontecimento passou e é irrecuperável.

Partindo dessa suposição, podemos analisar cada um dos nossos personagens. António Claro é um papel secundário no cinema, mas vem ganhando espaço, assim como a literatura atualmente. Ele vive da arte, arte de representar, segundo Aristóteles, o que poderia ter acontecido. Vive de altos e baixos, às vezes está filmando, às vezes não. Ele não é tão honesto quanto Tertuliano, gosta de encenar, tanto que obriga Tertuliano a deixá-lo passar uma noite com Maria da Paz, fazendo-se passar por Tertuliano. Disso podemos inferir que a Literatura, eventualmente, gosta de se fazer passar por História, gosta de tomar o seu lugar. Só se formos muito atentos para perceber as diferenças, como, por exemplo, a marca da aliança no dedo, como fez Maria da Paz, ou seja, num detalhe muito pequeno, perceberemos um engodo. Verificaremos o que não é história, mas literatura se fazendo passar por ela.

O uso de um nome artístico é outro indício da dissimulação de Daniel Santa-Clara. O ator também já é duplo, antes mesmo do aparecimento de Tertuliano. Ele é a pessoa António Claro, casado com Helena, e também é o ator secundário de filmes classe B: Daniel SantaClara. Tudo nele é ficção, até seu próprio nome é inventado e tem personalidade própria, tendo em vista que ele prefere que seu nome artístico seja chamado de heterônimo ao invés de pseudônimo. Isso conceitualmente implica na invenção de outro ser com características próprias distintas.

Já Tertuliano tem um emprego fixo e uma profissão honrada, mais nobre, mas menos prestigiada que a de António Claro. Num determinado momento ele diz:

$\mathrm{Eu}$, ao menos sou professor de história, murmurou. Uma declaração assim, que acintosamente tinha pretendido determinar e enfatizar a sua superioridade, não apenas profissional, mas também moral e social, em relação à insignificância do papel da personagem. (SARAMAGO, 2002, p.89). 
Ele ama Maria da Paz, mas precisou do distanciamento histórico para perceber isso: só depois que ela morreu foi que ele notou que realmente a amava. Ele é organizado e mais honesto, tem um vínculo afetivo grande com a mãe, que prevê seu destino. Esse vínculo com os ancestrais é mais uma ligação de Tertuliano com a História. António Claro não tem família, é um sujeito surgido do nada, sem origens; enquanto Tertuliano tem certeza de suas origens e sabe que é único, que nasceu sozinho. Todavia o autor problematiza a certeza dos fatos e ausência de imaginação no que é contado pela História, isso é revelado através de uma observação ao professor de História:

...o pior defeito deste homem, pelo menos desde que o conhecemos, tem sido o excesso de imaginação, na verdade ninguém diria que se trata de um professor de História a quem só os factos (sic) deveriam interessar, só por ter visto pelas costas a mulher que acaba de passar já o temos aqui a falsear identidades, ainda por cima de uma pessoa a quem não conhece, [...] Justiça deve ser feito no entanto a Tertuliano Máximo Afonso porque apesar de sua tendência para o desvairo imaginativo, ainda consegue, em momentos decisivos, sobrepor-lhe uma frieza de cálculo que faria empalidecer de ciúme profissional o mais encalecido dos especuladores da bolsa. (SARAMAGO, 2002, p.173.).

Assim, através da imaginatividade, a História se aproxima da Literatura. Em nosso enredo também Tertuliano também toma o lugar de António Claro, obviamente, por vingança; ambos, ao tomarem o lugar um do outro, parecem ficar mais excitados, mais felizes, por isso o tratamento deles para com as mulheres um do outro é tão diferente. Tertuliano aprecia mais a esposa de António Claro, enquanto este gosta mais da namorada daquele. Por fim, Tertuliano toma o lugar de António Claro definitivamente já que este morre. Isso simboliza o momento pós-moderno onde a História, mais especificamente a metaficção historiográfica, tomou conta do espaço ficcional. Só a História sobrevive, mas disfarçada de Literatura.

Uma passagem que traz à tona do discurso essa contenta filosófica é a seguinte:

A diferença não é grande, A nossa colega de Literatura diria que é, pelo contrário, enorme, e ela entende dessas coisas, creio que subtilezas e matizes a literatura é quase como a matemática, Já eu, pobre de mim, pertenço à área da História, onde os matizes e as subtilezas não existem, Existiriam se a História pudesse ser, digamos assim, o retrato da vida, Estou a estranhá-lo, não é próprio de si ser tão convencionalmente retórico, Tem toda a razão, em tal caso a História não seria a vida, apenas um dos retratos possíveis dela, parecidos, sim, mas nunca iguais. (SARAMAGO, 2002, p. 145-146.)

Logo, os dois personagens são falsos: História e Literatura são ficção e fictícios; o autor leva ao extremo à postulação pós-modernista da necessidade de autenticação dos saberes narrativos. $\mathrm{O}$ autor nos faz crer que ele pensa história como literatura, um relato que até certo ponto segue os fatos, mas é "cheia de inventividades".

Outro personagem interessante, como indício de leitura, é Carolina Máximo, mãe de Tertuliano. Ela prediz o destino, mas, assim como à Cassandra, ninguém a ouve:

mas aquela frase da mãe, Às vezes da maneira pior, quando, para a sossegar, ele tinha dito que neste mundo tudo se resolve, soavam-lhe agora a vaticínio de desastres, a núncio de 
fatalidades, como se, em lugar da idosa senhora que se chama Carolina Máximo e era sua mãe, lhe tivesse saído do outro lado do fio uma sibila ou uma Cassandra a dizer-lhe, por outras palavras, Ainda está em tempo de parar. (SARAMAGO, 2002, p. 137.).

Carolina, diferente de Cassandra, não tem o dom da premonição. Ela sabe o que acontecerá ao filho por conhecê-lo; da mesma forma que um entendido em história pode traçar linhas de acontecimentos que solucionarão determinado evento, por simples conhecimento de diversas situações semelhantes. Enfim, não é premonição, é analogia. E também é instinto maternal, de quem deu vida àquele sujeito e acompanhou sua formação.

Essa comparação com Cassandra é mais um índice da paródia que é feita com a história da guerra de Tróia. Temos vários outros elementos que a indicam. A paródia é outro conceito reaproveitado pelos pós-modernistas. Segundo Hutcheon, a paródia não é sátira, pois, no uso pós-modernista, é uma retomada que questiona e ressacraliza o texto mencionado. Outro indício dessa relação é o nome "Helena". Na história original, é a causadora da guerra, aqui, ela é posta como um personagem que simplesmente se acomoda às contingências. Mas como Helena de Tróia, ela troca de marido, seu marido oficial é António Claro, que morre, e em virtude de sua morte, acaba ficando com Tertuliano. Os dois sósias corresponderiam a Menelau e Paris, um apaixonado e o outro o marido por direito.

Não há guerra, pois existe outra mulher que é trocada por Helena. E ela é o elemento de paz: a Maria da Paz. Entretanto, existem mais questionamentos, o centro da troca não é Helena e sim Maria da Paz. Ela é objeto de desejo de António, assim como a guerra é objeto de desejo de Menelau, não Helena, pela qual ele só nutria um sentimento de posse. Isso nos leva a uma nova visão da guerra de Tróia, onde o grande motor da contenda não é Helena e sim a guerra. Menelau busca Helena, não por amá-la, mas por querer participar de uma nova guerra. $\mathrm{O}$ autor parece mostrar que existem aqui duas mulheres que são objetos de desejos dos homens envolvidos; logo, na versão original, também tínhamos dois objetos de desejo: Helena e a guerra.

Além disso, podemos ver os dois heróis desse texto. Tertuliano, o personagem guerreiro, coloca a práxis à frente da emoção, representa Menelau; um rei que também não valoriza as mulheres a seu redor, como Tertuliano faz com a mãe, com Maria da Paz e, evidentemente, com sua primeira esposa. Ele não é romântico, é um homem lacônico, enfim, somente utiliza as mulheres para chegar aos seus fins; como usa o nome de Maria da Paz para enviar a carta. Já António Claro é Páris, um jovem ator, com muita lábia e jeito com as mulheres. Ele seduz Maria da Paz tão encantadoramente que ela fica realizada, todavia como está apaixonada não percebe a troca, e, só ao ver a marca da aliança, percebe o engodo. 
É evidente que estamos diante de uma paródia, mas também é óbvio que essa é feita muito sutilmente, e só a partir de um conhecimento prévio bem consolidado por parte do leitor que é possível percebê-la. Todavia, é inegável a analogia já que são vários os elementos passíveis de aproximação. Para Hutcheon (1991, p. 28), a paródia "paradoxalmente, incorpora e desafia aquilo a que parodia. Ela também obriga a uma reconsideração da idéia de origem ou originalidade". Temos então a partir do que é retomado elementos para uma leitura daquele texto original.

Outro ponto importante na retomada pós-modernista são as questões formais. O texto usa categorias formais clássicas, como o coro, que tem, na tragédia clássica, o papel de trazer a opinião do senso comum sobre o conflito trágico e também o de ser o contraponto do herói. Aqui o personagem 'Senso comum' faz exatamente esse papel, ele conversa com o herói e entra em conflito com o mesmo já que os dois divergem tanto. O nome "Senso Comum" já é irônico por si só, o personagem ganha o nome de sua função, ou seja, a função do coro. A estrutura normal das obras que já superaram o uso do coro tem o senso comum expresso geralmente por um coadjuvante, companheiro do herói. Na obra, a ironia é colocá-lo sob o rótulo de senso comum. Enfim, o senso comum não é um companheiro assíduo da humanidade. E o autor contrapõe ao que recomenda o estilo dos gregos, está trazendo o modelo para discuti-lo, no caso para discordar dele:

... não é saudável para o espírito viver de casa e pucarinho com o senso comum, comer com ele à mesa, dormir com ele na cama, levá-lo ao trabalho, pedir-lhe sua aprovação ou consentimento antes de dar um passo, alguma coisa tereis de arriscar por vossa própria conta, A quem te referes, A vocês todos, ao gênero humano, (SARAMAGO, 2002, p.156.).

O destino, assim como nas tragédias clássicas , é anunciado desde o princípio. Não há espaço para dois iguais no mundo, um só sobreviverá, e isso está enunciado em: "Demos nós tempo ao tempo, e saberemos qual das duas vocações prevalecerá." (SARAMAGO, 2002, p. 165). E assim ocorre, Tertuliano teima com o destino de permanecer alheio ao seu sósia e é castigado com a perda de sua vida; não que ele morra, pois é António quem falece, mas António morre no lugar de Tertuliano, logo, quem perde sua vida é Tertuliano, não o corpo, mas o que ele representa na sociedade.

Também temos o homem que foge do destino que lhe foi traçado, sendo castigado. Por isso, os homens devem ficar na mediocridade, no caminho do meio, sem serem arrogantes ou torpes em demasia.

Cremos que esse texto é uma retomada paródica dos textos clássicos: no enredo, por remeter a guerra de Tróia e na forma por, apesar de ser um romance, indiciar diversos elementos da tragédia clássica, como o coro, a trajetória, o destino e o oráculo. Nessa obra 
estão unidos os principais conceitos da pós-modernidade: a paródia, a intertextualidade, a movimentação entre os diversos níveis de linguagem, o questionamento de todos os elementos, a metalinguagem e a metaficção historiográfica, marca principal da pósmodernidade. Tal como afirma Hutcheon (1991, p. 158): "Mais do que ambígua, a arte pósmoderna é duplicada e contraditória".

\section{Referências}

BAKTHIN, Mikhail. Marxismo e filosofia da linguagem. São Paulo: Hucitec, 1992.

ECO, Umberto. Obra aberta: forma e indeterminação nas poéticas contemporâneas. São Paulo: Perspectiva, 1991.

HUTCHEON, Linda. A poética do Pós-modernismo. Rio de Janeiro: Imago, 1991.

JAMESON, Frederic. Pós-Modernismo: a lógica cultural do capitalismo tardio. São Paulo: Ática, 1997.

MACHADO, Ronaldo Silva. História e poesia na poética de Aristóteles. Disponível em: http://www.seol.com.br/mneme/ed3/013-p.htm, Acesso em 16 de novembro de 2005.

REIS. Luzia de Maria R. O que é conto. São Paulo: Brasiliense, 1987, p. 86.

SARAMAGO, José. O homem duplicado. São Paulo: Companhia das Letras, 2002.

STRAHLER, Eulina Aparecida. Dicionário de nomes. Disponível em http://paginas.terra.com.br/saude/oconsultorio1/Tres.htm. Acesso em 02 de dezembro de 2005. 